\title{
Ethylene-Propylene Copolymer/Ordered Poly(silsesquioxane) Nanocomposites Prepared via Organic Acid- or Base-Catalyzed Binary Silica Water-Crosslinking Reactions
}

Kenta ADACHI ${ }^{1 *}$, Tomoyuki HIRANO ${ }^{2}$, Paul H. KASAI $^{2}$, Katsuhiko NAKAMAE $^{2}$, Hitoshi IWABUKI ${ }^{3}$, and Koji MURAKAMI ${ }^{3}$.

* To whom correspondence should be addressed. E-mail: adachi@yamaguchi-u.ac.jp

(1) Department of Environmental Science \& Engineering, Graduate School of Science \& Engineering, Yamaguchi University, Yamaguchi, 753-8512, Japan. Tel \& Fax: +81-83-933-5731.

(2) Frontier Research \& Development Department, Matsumura Oil Research Corporation (MORESCO), Kobe, Hyogo, 650-0047, Japan.

(3) Industrial Technology Center of Okayama Prefecture, Okayama, 701-1296, Japan

Keyword: Alkoxysilane, Polyolefin, Silsesquioxane, Amine, and Sulfonic acid. 


\begin{abstract}
BACKGROUND: In-situ silica sol-gel derived organic-inorganic hybrid materials, which comprise a vinyltrimethoxysilane-grafted ethylene-propylene copolymer (EPR-g-VTMS) and $n$-hexyltrimethoxysilane (HTMS), were successfully prepared in the presence of an organic acid and base catalyst. Benzenesulfonic acid $\left(\mathrm{PhSO}_{3} \mathrm{H}\right)$ and aniline $\left(\mathrm{PhNH}_{2}\right)$ were selected as the organic acid and base catalyst, respectively, to examine the progress and effect of progressive changes in the silane water-crosslinking reaction of EPR-gVTMS/HTMS composites.
\end{abstract}

RESULTS: The water-crosslinked EPR-g-VTMS/HTMS composites were characterized by means of attenuated total reflectance-Fourier transform infrared spectroscopy (ATR-FTIR), solid-state silicon-29 cross polarization/magic angle spinning-nuclear magnetic resonance $\left({ }^{29} \mathrm{Si} \mathrm{CP} / \mathrm{MAS} \mathrm{NMR}\right)$, wide-angle X-ray scattering (WAXS), tensile strength, and field emission-scanning electron microscope (FE-SEM) measurements.

CONCLUSION: These results revealed that the type of catalyst has a substantial influence on the nature of siloxane bands and eventually the physical tensile properties of the water-crosslinked EPR-g-VTMS/HTMS composites, which can be explained mainly on the knowledge of the traditional acid- and base-catalyzed silica sol-gel reaction. Moreover, the in-depth analysis for the $\mathrm{PhNH}_{2}$-catalyzed composites indicated the formation of ladder-type poly(n-hexyl silsesquoxane)s and the presence of the highly-ordered structure with a thickness equal to the length of two $n$-hexyl groups in all-trans conformation. In the present study, we demonstrated a potential for future design of highly-ordered silicate-based organic-inorganic hybrid nanocomposites. 


\section{INTRODUCTION}

Polyolefins (POs) are saturated hydrocarbon polymers based on ethylene, propylene and higher $\alpha-$ olefins or combinations of these monomers. Nowadays, POs have become the most used thermoplastic resin in a wide range of applications, such as cables, pipes, sheets, films, and adhesive [1-3]. However, there are some natural shortcomings of POs, which are the limits of thermal stability and large permanent distortion. As a method for overcoming these shortcomings, the crosslinking technology and organic-inorganic hybrid materials have attracted great interest over the last decade.

Presently, there are three commercial methods used for the crosslinking of POs: (i) peroxide crosslinking [4], (ii) radiation crosslinking [5], and (iii) silane water-crosslinking [6]. Each method has its own applications according to its particular advantages. The last crosslinking technology is based on the traditional silica sol-gel chemistry [7]. The alkoxysilane groups can be easily grafted onto PO backbone by a free-radical reaction [9]. The alkoxysilane hydrolysis and condensation reactions leading to watercrosslinked POs are shown as follows:

Hydrolysis:

$$
\mathrm{R}-\mathrm{Si}-\mathrm{OR}^{\prime}+\mathrm{H}_{2} \mathrm{O} \rightleftharpoons \mathrm{R}-\mathrm{Si}-\mathrm{OH}+\mathrm{R}^{\prime}-\mathrm{OH}
$$

\section{Condensation:}

$$
2 \mathrm{R}-\mathrm{Si}-\mathrm{OH} \rightleftharpoons \mathrm{R}-\mathrm{Si}-\mathrm{O}-\mathrm{Si}-\mathrm{R}+\mathrm{H}_{2} \mathrm{O}
$$

This silane water-crosslinking reaction (hydrolysis and condensation) is interest from the viewpoint of environmentally friendly chemistry, because alkoxysilane as a water-crosslinkable group is non-toxic and the use of water as a reaction trigger automatically leads to a green feeling amongst consumers.

The organic-inorganic hybrid materials offer the opportunity to combine the desirable properties of organic polymers (toughness, elasticity) with those of inorganic solids (hardness, heat and chemical resistance). There are three principal procedures commonly employed to disperse inorganic fillers in a polymeric matrix: (i) blending in solution [10], (ii) blending in melt [11-12], (iii) in-situ sol-gel processing 
[13-15]. The first solution process is simple, but uses a large amount of organic solvent. The second melt blending method is environmentally benign due to the absence of organic solvents, and it is also compatible with current industrial processes, such as extrusion and injection molding. For instance, PO/clay and PO/silicate nanocomposite techniques using an extruder are now being conducted globally [16-22]. Despite many efforts in this field, this method can hardly result in nanocomposites without particle agglomeration because of the poor compatibility of inorganic fillers with PO matrices. In-situ sol-gel process is based on the blending of alkoxysilane compounds with PO matrix and the subsequent hydrolysis-condensation reaction of the alkoxysilane compounds (see Eqs. (1) and (2)). The organic-inorganic hybrid materials made in this process are normally nanocomposites and have the potential for providing unique combinations of properties which cannot be achieved by other materials. Recently, poly(silsesquioxane) compounds, which are composed of a monomer repeat unit $\left(\mathrm{RSiO}_{1.5}\right)$ with a single silicon atom attached to other repeat units through up to three siloxane bonds (-Si-O-Si-) and to an organic group ( $\mathrm{R})$ through a silicon-carbon single bond (-Si-C-), have rapidly become the subject of intensive study as a vehicle for introducing various functionalities into organic-inorganic hybrid materials through the in-situ sol-gel processing [23-27].

Inspired by this in-situ sol-gel approach, we propose a new organic-inorganic hybrid material design using vinyltrimethoxysilane-grafted ethylene-propylene copolymer (EPR-g-VTMS) and $n$ hexyltrimethoxysilane (HTMS, trifunctional silicon alkoxide). EPR-g-VTMS is selected as the reactive PObased matrix in this study. HTMS has good compatibility with PO matrix and can form poly $(n$-hexyl silsesquioxane)s through the hydrolysis and condensation reaction. Because the methoxysilane groups in EPR-g-VTMS matrix are able to react with the silanol groups on in-situ formed poly $(n$-hexyl silsesquioxane)s during the water-crosslinking reaction, we expect that the water-crosslinked EPR-gVTMS/HTMS composites should be eventually a highly-dispersed organic-inorganic hybrid materials. In this article, we report on the EPR-g-VTMS/HTMS composites with focus on the chemical and structural 
characterization and on the morphology. Moreover, the effect of the catalyst on the silane water-crosslinking reaction in EPR-g-VTMS/HTMS composites is also described. 


\section{EXPERIMENTAL}

\subsection{Materials.}

The ethylene-propylene copolymer (EPR) with $M_{\mathrm{w}}=2.77 \times 10^{4} \mathrm{~g} / \mathrm{mol}, M_{\mathrm{w}} / M_{\mathrm{n}}=2.3\left(M_{\mathrm{w}}\right.$ : weightaverage molecular weight, $M_{\mathrm{n}}$ : number-average molecular weight), crystallinity $=34.9$ wt $\%$, and ethylene/propylene molar ratio $=10.1 / 89.9$ was kindly supplied by Clariant Japan K.K. (Tokyo, Japan). Vinyltrimethoxysilane (VTMS), n-hexyltrimethoxysilane (HTMS), and dicumyl peroxide (DCP) were purchased from Dow Coring Toray (Tokyo, Japan) and NOF (Tokyo, Japan), respectively. Acetone ( 98\%), chloroform ( 99.5\%) was received from Nacalai Tesque Inc., (Kyoto, Japan). Benzenesulfonic acid $\left(\mathrm{PhSO}_{3} \mathrm{H}\right)$ and aniline $\left(\mathrm{PhNH}_{2}\right)$, which selected as a silane-crosslink catalyst, were supplied by Wako Pure Chemicals (Osaka, Japan). All materials were used as received without further purification.

\subsection{Preparation.}

According to the procedure described earlier [28], the vinyltrimethoxysilane-grafted ethylenepropylene copolymer (EPR-g-VTMS) with VTMS concentration of $5 \mathrm{phr}$ (part of reagent per hundred parts of EPR polymer by weight) was prepared in the molten state by the use of DCP as an initiator. The blending of HTMS with EPR-g-VTMS matrix was performed in an open-kneader SV0.5-0.5 (Moriyama, Japan) equipped with two blades co-rotating at $50 \mathrm{rpm}$. EPR-g-VTMS was introduced into the chamber heated at $120{ }^{\circ} \mathrm{C}$ and, after $10 \mathrm{~min}$, HTMS was added to attain $10 \mathrm{phr}$ final concentrations. After mixing for $20 \mathrm{~min}$, the crosslink catalyst of choice, in the amount of $5.0 \times 10^{-4} \mathrm{~mol} / 100 \mathrm{~g}$ EPR resin, was added. The product was removed from the chamber, and shaped into $c a .0 .5 \mathrm{~mm}$-thick compression-moulded sheets by air pressing. To conduct a silane water-crosslinking reaction, the sample sheets were immersed into hot water $\left(80^{\circ} \mathrm{C}\right)$ for a defined time. The preparation procedure of water-crosslinked EPR- $g$-VTMS/HTMS composites is depicted in Scheme 1. 


\subsection{Characterization.}

Fourier transform infrared (FTIR) spectroscopy was used to follow the alkoxysilane hydrolysiscondensation reaction in EPR-g-VTMS/HTMS composites. The IR spectra were recorded using a MAGNAIR 560 FT-IR spectrometer (Nicolet, USA) equipped with a single reflection Ge attenuated total reflectance accessory (Thunder-dome, Spectra-Tech. Inc., USA) in the range of $600-4000 \mathrm{~cm}^{-1}$ with a resolution of 4 $\mathrm{cm}^{-1}$. The average of 64 spectra was used to increase the signal to noise ratio.

Solid-state ${ }^{29} \mathrm{Si}$ cross polarization/magic-angle spinning (CP/MAS) NMR analysis was performed on a JNM-CMX-400 spectrometer (JEOL, Japan) at a resonance frequency of $79.42 \mathrm{MHz}$, with a pulse width of $45^{\circ}$, and a recycle delay of $100 \mathrm{sec}$. In all cases, high-power proton decoupling was used, and the chemical shifts were externally referenced to tetramethylsilane. Deconvolution of spectra was performed by using a Gaussian function on an ORIGIN software version 6.1 (Originlab, USA). According to the Glaser's nomenclature [29], the silanes are denoted in this article, using $T^{m}(m=0,1,2,3)$ where $m$ refers to the number of siloxane bridges bonded to the silicon atom.

X-ray scattering analysis was performed on a Bruker D8 Discover X-ray Diffractometer (Bruker AXS, USA) operating at room temperature. Graphite-monochromatized $\mathrm{CuK} \alpha$ beam $(\lambda=1.5418 \AA ⿻$ was transmitted through the sample sheet. The profile analyses were made by software of DIFFRAC ${ }^{\text {plus }}$ TOPAS (Bruker AXS, USA).

Tensile properties of the water-crosslinked EPR-g-VTMS/HTMS composites were performed with a tensile tester AUTOGRAPH AGS-H 500N (Shimadzu Co. Ltd., Japan). The measurements were carried out by using tensile speed of $100 \mathrm{~mm} / \mathrm{min}$ in a room thermostated at $25 \pm 2{ }^{\circ} \mathrm{C}$. The dumbbell specimens (no. 6 of Japan Industrial Standard, JIS K 6251) were subjected to the measurement.

The morphological analysis of fracture surfaces of the EPR-g-VTMS/HTMS composites has been carried out on a field emission scanning electron microscopy (FE-SEM) microscope (JSM-6340F, JEOL, 
Japan) operating at $5 \mathrm{kV}$. The fracture surfaces were coated with a thin platinum film in an auto fine coater (JEE-420T, JEOL, Japan). 


\section{RESULTS AND DISCUSSION}

\subsection{Chemical and Structural Characterization of Water-Crosslinked EPR-g-VTMS/HTMS}

\section{Composites.}

\subsubsection{Attenuated Total Reflectance-Fourier Transform Infrared Spectroscopy (ATR-FTIR). An}

attenuated total reflectance-Fourier transform infrared (ATR-FTIR) measurement can be regarded as a powerful tool to study the alkoxysilane hydrolysis-condensation process. [30-32] As a comparison between $\mathrm{PhSO}_{3} \mathrm{H}$ and $\mathrm{PhNH}_{2}$ catalyst used in this study, the ATR-FTIR spectra of EPR-g-VTMS/HTMS composites under the same water-crosslinking reaction conditions are depicted in Fig. 1(a) and (b), respectively. In both initial spectrum, the absorption peaks at 1095 and $1193 \mathrm{~cm}^{-1}$ are corresponding to $\mathrm{Si}-\mathrm{O}$ stretching and $\mathrm{Si}-\mathrm{C}$ stretching vibration of the methoxysilane groups $\left(\mathrm{C}-\mathrm{Si}-\mathrm{OCH}_{3}\right)$ in VTMS and HTMS moieties, respectively, [33-36] and then the ones decrease monotonically with aging time. In the $\mathrm{PhSO}_{3} \mathrm{H}$-catalyzed composite, new absorption bands at 980 and $1048 \mathrm{~cm}^{-1}$ appeared, which were attributed to silanol (-Si-OH) and single siloxane linkages (-Si-O-Si-), respectively, [37] and their intensities increased with aging time. However, for the case using $\mathrm{PhNH}_{2}$ catalyst, new absorption peaks at 1048 and $1120 \mathrm{~cm}^{-1}$ developed with aging time, while the silanol band at $980 \mathrm{~cm}^{-1}$ not. It is known that two bands centered around 1040 and $1100 \mathrm{~cm}^{-1}$ evidence multi siloxane linkages $\left(-\mathrm{Si} \equiv(\mathrm{O})_{3} \equiv \mathrm{Si}-\right)$ of water-crosslinked EPR-g-VTMS [37] and/or a cis-

syndiotactic ladder configuration of poly(n-hexyl silsesquioxane) (see Scheme 2) [38-40]. The spectral difference between $\mathrm{PhSO}_{3} \mathrm{H}$ and $\mathrm{PhNH}_{2}$ catalyst is consistent with our previous reports on the silane watercrosslinking reaction of EPR-g-VTMS in the presence of various sulfonic acid and amine compounds [41], which is understandable on the traditional knowledge of acid- and base-catalyzed silica sol-gel reaction [7].

\subsubsection{Solid-State Silicon-29 Cross Polarization/Magic Angle Spinning-Nuclear Magnetic Resonance} ( ${ }^{29}$ Si CP/MAS-NMR). The solid-state cross polarization/magic angle spinning-nuclear magnetic resonance technique for silicon-29 $\left({ }^{29} \mathrm{Si} \mathrm{CP} / \mathrm{MAS} \mathrm{NMR}\right)$ can supplement the information provided by FTIR 
spectroscopy for the silica and silicon materials [42]. The conversion attained in the polycondensation for the water-crosslinked EPR-g-VTMS/HTMS composites was also investigated by ${ }^{29} \mathrm{Si}$ CP/MAS NMR measurement. Figure 2 shows the corresponding the solid-state ${ }^{29} \mathrm{Si} \mathrm{CP} / \mathrm{MAS} \mathrm{NMR}$ spectra for $\mathrm{PhSO}_{3} \mathrm{H}-$ and $\mathrm{PhNH}_{2}$-catalyzed composites (aged in $80^{\circ} \mathrm{C}$ water for 24 hours). The ${ }^{29} \mathrm{Si}$ resonances observed at around -49 , -58, and $-68 \mathrm{ppm}$ in Figure 2(a) and (b) can be associated with the general silsesquioxane structures $(\mathrm{HO})_{2}(\mathrm{R}) \mathrm{Si}(\mathrm{OSi})\left[T^{1}\right.$ structure], $(\mathrm{HO})(\mathrm{R}) \mathrm{Si}(\mathrm{OSi})_{2}\left[T^{2}\right.$ structure], and $(\mathrm{R}) \mathrm{Si}(\mathrm{OSi})_{3}\left[T^{3}\right.$ structure], respectively, where $\mathrm{R}$ is EPR backbone or $n$-hexyl group in this study [29,43-44]. Moreover, the absence of resonances at ca. $-40 \mathrm{ppm}$, corresponding to $(\mathrm{R}) \mathrm{Si}(\mathrm{OH})_{4}\left[T^{0}\right.$ structure $]$, implies that all of the silicon atoms in both watercrosslinked EPR-g-VTMS/HTMS composites are involved in some degree of $\mathrm{Si}-\mathrm{O}-\mathrm{Si}$ crosslinks. From the peak deconvolution by a nonlinear least square method using Gaussian function, the integrated peak area ratios $\left(T^{1} / T^{2} / T^{3}\right)$ of Fig. 2(a) and (b) were determined to be 14.4/57.1/28.5 and 0.1/5.3/94.6, respectively. In the case using $\mathrm{PhSO}_{3} \mathrm{H}$ catalyst (Fig. 2(a)), the observation of a sizeable population of $T^{2}$ structures indicates a general structure consisting of extended linear siloxane chains with isolated silanols. Moreover, it is interesting to note that the relative proportion of the $T^{3}$ environments is higher in Fig. 2(b), clearly indicating that the higher degree of condensation for stable and complete siloxane network is achieved using $\mathrm{PhNH}_{2}$ catalyst. In this $\mathrm{PhNH}_{2}$-catalyzed system, the high conversion attained in the inorganic polycondensation suggests that silsesquioxane domains are present as polyhedra or ladder structures. [45-50]

In the previous section where the hydrolysis-condensation process was examined by means of ATRFTIR technique, it was run that, in the $\mathrm{PhSO}_{3} \mathrm{H}$-catalyzed composite, the condensation step did not progress to the same extent achieved by $\mathrm{PhNH}_{2}$ catalyst (see Fig. 1). Therefore, it is reasonable that there is a significant difference between both ${ }^{29} \mathrm{Si}$ CP/MAS NMR spectra in Fig. 2. This joint evidence provided by ${ }^{29} \mathrm{Si} \mathrm{CP/MAS} \mathrm{NMR} \mathrm{and} \mathrm{ATR-FTIR} \mathrm{results} \mathrm{points} \mathrm{out} \mathrm{to} \mathrm{the} \mathrm{presence} \mathrm{of} \mathrm{poly(n-hexyl} \mathrm{silsesquioxane)s} \mathrm{as}$ linear siloxane chain structures with isolated silanols and cis-syndiotactic ladder structures in the $\mathrm{PhSO}_{3} \mathrm{H}$ and $\mathrm{PhNH}_{2}$-catalyzed EPR-g-VTMS/HTMS composites, respectively. 
3.1.3 Wide-Angle X-Ray Scattering (WAXS). The wide-angle X-ray scattering (WAXS) profiles of the uncrosslinked (as-prepared) and water-crosslinked EPR-g-VTMS/HTMS composites, compared with that of the corresponding virgin EPR sample, are reported in Fig. 3. In the wide-angle range $\left(2 \theta>10^{\circ}\right)$, WAXS patterns on the all samples show the typical crystal form of isotactic polypropylene (iPP) [2]. Generally, iPP samples characterized by chains including different types of microstructural defects (i.e., stereo- and regiodefects) crystallize as a mixture of the $\alpha$ and $\gamma$ forms. [51-55] The virgin EPR sample crystallizes in the $\alpha$ form, as indicated by the presence of the (130) $\alpha$ reflection at $2 \theta=18.6^{\circ}$ of the $\alpha$ form and the absence of the (117) $\gamma$ reflection at $2 \theta=20.1^{\circ}$ of the $\gamma$ form [53-55] in the WAXS profile A of Fig. 3. However, the low intensity of the (130) $\alpha$ reflection suggests the presence of disordered modifications intermediate between $\alpha$ and $\gamma$ forms [56]. Antithetically, EPR-g-VTMS/HTMS composites before and after water-crosslinking reaction (profiles B-D) mainly crystallized in the $\gamma$ form, as indicated by the presence of the strong scattering peak of the $\gamma$ form and the weak scattering peak of the $\alpha$ form, suggesting that the grafted-VTMS moieties onto EPR skeleton and/or the addition of HTMS into EPR-g-VTMS system exert the stereo- and/or regioneffects in inducing the crystallization of the $\gamma$ form. Since it is well-known that interruptions in the regular sequences of iPP favored the development of the $\gamma$ form [57], these WAXS results seems to be reasonable. Although similar WAXS profiles in the wide-angle range were observed before and after water-crosslinking reaction in both catalyst cases, the major differences in the small-angle range $\left(2 \theta<10^{\circ}\right)$ did exist. Actually, as shown in the small-angle range WAXS profiles $\mathrm{C}$ and $\mathrm{E}$ of Fig. 3 (left side), a scattering peak at $2 \theta=5.1^{\circ}$ was observed but different in scattering magnitude, indicating that the water-crosslinked EPR-gVTMS/HTMS composites have a typical ordered-structure with a basal spacing of ca. $1.7 \mathrm{~nm}$. The presence of the same correlation distance for $\mathrm{PhSO}_{3} \mathrm{H}$ - and $\mathrm{PhNH}_{2}$-catalyzed composite implies that the layer formation process was not affected to a significant extent by the presence of the selected catalysts. This spacing value refers to the chain length of two $n$-alkyl groups (ca. $1.8 \mathrm{~nm}$ in all-trans conformations) between 
cis-syndiotactic ladder structures of poly(n-hexyl silsesquioxane)s calculated by the AM1 method on the software HyperChem 7.1 [58], as shown in Scheme 2. The possible structure of water-crosslinked EPR-gVTMS/HTMS composites will be discussed later in detail.

3.1.4 Tensile Strength. Tensile stress-strain curves of water-crosslinked EPR-g-VTMS/HTMS composites catalyzed by $\mathrm{PhSO}_{3} \mathrm{H}$ and $\mathrm{PhNH}_{2}$ (aged in $80^{\circ} \mathrm{C}$ water for 24 hours) are shown in Fig. 4 . As references, the stress-strain curve of uncrosslinked EPR-g-VTMS/HTMS (as-prepared) is displayed in this figure. The stress-strain curve generally uses to characterize the dynamic behavior of crosslinked polymer. The drawing curve of uncrosslinked sample, which shows the characteristic yield drop around $25 \%$ elongation and a plateau region (neck formation) and afterwards breaks (4.2 $\mathrm{MPa}, 439 \%)$, is conventional behavior as an uncrosslinked polyolefin resin [59]. Both water-crosslinked EPR-g-VTMS/HTMS composite samples show an improvement of all the mechanical parameters. However, the drawing behavior shows some relevant differences depending upon the catalyst used. The $\mathrm{PhSO}_{3} \mathrm{H}$-catalyzed composite shows a small interval in which the stress, after the yield point at about $20 \%$ elongation, remains constant. This interval is followed by strain-hardening that produces the fracture at the lower stress and higher elongation (9.7 MPa, $291 \%)$. On the other hand, the $\mathrm{PhNH}_{2}$-catalyzed composite shows the increase of the stress value at the yield point as well as the elastic modulus, but rapidly breaks at the higher stress and lower elongation (12.8 MPa, 168\%). Of course, these tensile behaviors of $\mathrm{PhSO}_{3} \mathrm{H}$ - and $\mathrm{PhNH}_{2}$-catalyzed composites should reflect a result of the overall water-crosslinking reaction degree in EPR-g-VTMS/HTMS composite. It is worth mentioning that these differences in the tensile modulus and elongation depending on the type of the catalyst can be consistent with the one in the above experimental results (ATR-FTIR and ${ }^{29} \mathrm{Si} \mathrm{CP/MAS-NMR}$ ).

3.1.5 Field Emission-Scanning Electron Microscope (FE-SEM). Figure 5(a)-(c) exhibits the field emission-scanning electron microscope (FE-SEM) images of tensile fractured surface of the water- 
crosslinked EPR-g-VTMS/HTMS composites in the presence of $\mathrm{PhSO}_{3} \mathrm{H}$ and $\mathrm{PhNH}_{2}$ catalyst. In both catalyst results, the macro phase separation of HTMS from EPR-g-VTMS matrix (e.g. such as a micrometersize particle or domain) is not observed at the fractured surface, indicating good compatibility between HTMS molecules and EPR-g-VTMS matrix. As shown in Fig. 5(a), water-crosslinked EPR-g-VTMS/HTMS composite containing $\mathrm{PhSO}_{3} \mathrm{H}$ catalyst displays relatively flat and smooth surface having somewhat sharp tip. However, $\mathrm{PhNH}_{2}$-catalyzed system shows that the fracture surface is wedge-shaped. (see Fig. 5(b)) A magnification of one of these wedge-shaped areas is shown in Fig. 5(c). This large magnification FE-SEM image of the $\mathrm{PhNH}_{2}$-catalyzed composite exhibited the platy morphologies (ca. $100 \mathrm{~nm}$-thick) at the fractured surface. Another evidence of the presence of the ordered-structure was obtained from the cross section FE-SEM image using liquid nitrogen (Figure 5(d)). Plate-like morphology is observed. This finding may suggest that the water-crosslinked EPR-g-VTMS/HTMS composite (especially using $\mathrm{PhNH}_{2}$ catalyst) has a self-assembled structure consisting of a highly-ordered siloxane network.

\subsection{Absolute Configuration of Water-Crosslinked EPR-g-VTMS/HTMS Composites.}

From the above results of ATR-FTIR, ${ }^{29} \mathrm{Si} \mathrm{CP} / \mathrm{MAS}$ NMR, WAXS, tensile strength, FE-SEM measurements, we now consider the configuration of water-crosslinked EPR-g-VTMS/HTMS composites. As a typical case, we discuss on the $\mathrm{PhNH}_{2}$-catalyzed composite which shows an interesting platy morphologies and a much more pronounced improvement of physical properties than the $\mathrm{PhSO}_{3} \mathrm{H}$-catalyzed one. Concerning the highly-ordered structure of the water-crosslinked EPR-g-VTMS/HTMS composites containing $\mathrm{PhNH}_{2}$ catalyst, experimental results support the following facts: (i) poly( $n$-hexyl silsesquioxane) domains are mainly organized in ladders (ATR-FTIR and ${ }^{29} \mathrm{Si}$ CP/MAS-NMR); (ii) about 95\% of silicon atoms are present in $T^{3}$ structures $\left({ }^{29} \mathrm{Si} \mathrm{CP} / \mathrm{MAS}-\mathrm{NMR}\right)$; (iii) highly-ordered layers are separated by a characteristic distance of ca. $1.7 \mathrm{~nm}$ which corresponds to the length of two $n$-hexyl chains (WAXS); (iv) there is a periodicity such as a self-assembled structure (FE-SEM). Recent much research has shown that 
siloxane-based organic-inorganic hybrid materials prepared by the hydrolysis-condensation of alkoxysilane compounds can be controlled at the nanometer length scale through self-assembly. For instance, the formation of a layer structure composed of alkyl chains with all-trans conformations has been reported for the products obtained by the hydrolytic condensation of alkyltrialkoxysilanes or alkyltrichlorosilanes (12-18 carbon atoms in the alkyl group) [60-65]. Those results are an aid in understanding the formation of the highly-ordered structure in water-crosslinked EPR-g-VTMS/HTMS composites. A schematic representation of a basic structure satisfying the experimental findings and the steric restrictions is shown in Scheme 3 . In this proposed model, the basic ladder-type structures of poly(n-hexyl silsesquoxane)s are stacked together by a self-assembly of $n$-hexyl chains exhibiting all-trans conformations. This organization eventually generates a bilayer structure separated by hydrophobic n-hexyl groups. To our knowledge, this is the first time that ladder-type silsesquoxane bilayers are reported in the crosslinked polymer materials. In addition, a major factor in the formation of the platy morphologies seen here may be due to the micro phase separation (several nm-size) between HTMS and EPR-g-VTMS matrix before or during water-crosslinking reaction as described in Scheme 3, although the detail mechanism is still not known. Further investigation of the watercrosslinking reaction of various alkylalkoxysilane compounds in the same EPR-g-VTMS matrix will be the subject of future study. 


\section{CONCLUSION}

Vinyltrimethoxysilane-grafted ethylene-propylene copolymer/n-hexyltrimethoxysilane (EPR-gVTMS/HTMS) composite was prepared by an in-situ sol-gel processing. The water-crosslinking reaction of the EPR-g-VTMS/HTMS composites in the presence of organic acid or base catalysts $\left(\mathrm{PhSO}_{3} \mathrm{H}\right.$ or $\mathrm{PhNH}_{2}$, respectively) was investigated using the means of ATR-FTIR, ${ }^{29} \mathrm{Si}$ CP/MAS NMR, WAXS, tensile strength, and FE-SEM measurements. We found that the type of catalyst (acid or base) had a substantial influence on the nature of siloxane bands and eventually the physical tensile properties, which was understandable on the traditional knowledge of silica sol-gel chemistry. Moreover, for the $\mathrm{PhNH}_{2}$-catalyzed composites, experimental evidence indicated the formation of ladder-type poly ( $n$-hexyl silsesquoxane)s and the presence of the highly-ordered structure with a thickness equal to the length of two $n$-hexyl groups in all-trans conformation (see Schemes 2 and 3). Actually, the platy morphologies were observed on a microscopic scale. The present water-crosslinked EPR-g-VTMS/HTMS composite, which has a self-assembled structure consisting of a highly-ordered siloxane network, is unique and has a potential for future design of silicatebased organic-inorganic hybrid polymer nanocomposites. 


\section{References}

[1] Seymour RB, Cheng TC (eds). Advances in Polyolefins: The World's Most Widely Used Polymers 1st ed., Springer-Verlag, NY, USA. (1988)

[2] Vasile C (ed). Handbook of Polyolefins 2nd ed., CRC press, FL, USA. (2000)

[3] Nwabunma D, Kyu T (eds). Polyolefin Blends, Wiley-Interscience, NJ, USA. (2007)

[4] Smedberg A, Hjertberg T, Gustafsson B. Polymer, 2003;44:3395-3405.

[5] Gheysari D, Behjat A. Eur. Polym. J., 2001;37:2011-2016.

[6] Wang Z, Hu Y, Gui Z, Zong R, Polymer Testing, 2003;22:533-538.

[7] Wright JD, Sommerdijk NAJM, Sol-Gel Materials: Chemistry and Applications, CRC press, FL, USA. (2000)

[8] Hench LL, West JK, Chem. Rev., 1990;90:33-72.

[9] Al-Malaika S (ed), Reactive modifiers for polymers. Blackie Academic and Professional, London, UK. (1997)

[10] Hong RY, Fu HP, Zhang YJ, Liu L, Wang J, Li HZ, Zheng Y. J. Appl. Polym. Sci. 2007;105:21762184

[11] Yudin VE, Divoux GM, Otaigbe JU, Svetlichnyi VM, Polymer, 2005;46:10866-10872.

[12] Pluta M, Paul MA, Alexandre M, Dubois P. J. Polym. Sci. Part B Polym. Phys., 2006;44:299-311.

[13] Mizutani Y, Nago S. J. Appl. Polym. Sci., 1999;72:1489-1494.

[14] Muh E, Frey H, Klee JE, Mulhaupt R. Adv. Funct. Mater., 2001;11:425-429

[15] Jain S, Goossens H, Picchioni F, Magusin P, Mezari B, van Duin M. Polymer, 2005;46:6666-6681.

[16] Matsumura T, Ochi M, Nagata K. J. Appl. Polym. Sci., 2003;90:1980-1984.

[17] Hasegawa N, Okamoto H, Usuki A, J. Appl. Polym. Sci., 2004;93:758-764.

[18] Lew CY, Murphy WR, McNally GM. Polym. Eng. Sci., 2004;44:1027-1035.

[19] Felix AHO, Cardozo NSM, Nachtigall SMB, Mauler RS. Macromol. Mater. Eng., 2006;291:418-427.

[20] Okada A, Usuki A. Macromol. Mater. Eng., 2006;291:1449-1476.

[21] Tetsuka H, Ebina T, Nanjo H, Mizukami F. J. Mater. Chem., 2007;17:3545-3550.

[22] Shim JH, Joo JH, Jung SH, Yoon J-S. J. Polym. Sci. Part B: Polym. Phys., 2007;45:607-615.

[23] Zhang Z. Langmuir, 1997;13:473-476.

[24] Loy DA, Baugher BM, Baugher CR, Schneider DA, Rahimian K. Chem. Mater., 2000;12:3624-3632.

[25] Matějka L, Dukh O, Hlavatá D, Meissner B, Brus J. Macromolecules, 2001;34:6904-6914.

[26] Zheng L, Hong S, Cardoen G, Burgaz E, Gido SP, Coughlin EB. Macromolecules, 2004;37:86068611. 
[27] Zucchi IA, Galante MJ, Williams RJJ, Franchini E, Galy J, Gérard J-F. Macromolecules, 2007, 40, 1274-1282.

[28] Adachi K, Hirano T, Fukuda K, Nakamae K. Macromol. React. Eng., 2007;1:313-320.

[29] Glaser RH, Wilkes GL, Bronnimann CE. J. Non-Cryst. Solids, 1989;113:73-87.

[30] Bauer F, Decker U, Dierdorf A, Ernst H, Heller R, Liebe H, Mehnert R. Prog. Org. Coat., 2005;53:183-190.

[31] Adachi K, Hirano T. Eur. Polym. J., 2008;44:542-549.

[32] Adachi K, Hirano T. Ind. Eng. Chem. Res., 2008;47:1812-1819.

[33] Socrates G, Infrared and Raman Characteristic Group Frequencies: Tables and Charts (3rd Edition), John Wiley \& Sons, New York, USA. (2001)

[34] Silverstein RM, Bassler GC, Morrill TC, Spectrometric Identification of Organic Compounds (5th Edition), John Wiley \& Sons, New York, USA. (1991)

[35] Brandrup J, Immergut EH (eds). Polymer Handbook, (3rd Edition), John Wiley \& Sons, NY, USA. (1989).

[36] Hjertberg T, Palmlof M, Sultan B-A. J. Appl. Polym. Sci., 1991;42:1185-1192.

[37] Gazel A, Lemaire J, Laurenson P, Roche G. Makromol. Chem. Rapid Commun., 1985;6:235-240.

[38] Brown Jr. JF, Vogt Jr. LH, Prescott PI. J. Am. Chem. Soc., 1964:86;1120-1125.

[39] Brown Jr. JF, Vogt Jr. LH. J. Am. Chem. Soc., 1965;87:4313-4317.

[40] Suyama K, Gunji T, Arimitsu K, Abe Y. Organometallics, 2006;25:5587-5593.

[41] Adachi K, Hirano T. J. Sol-Gel Sci. Tech., 2009;49:186-195.

[42] Romeo HE, Fanovich MA, Williams RJJ, Matějka L, Pleštil J, Brus J. Macromolecules, 2007; $40: 1435-1443$.

[43] Ji X, Jiang S, Qiu X, Dong D, Yu D, Jiang B. J. Appl. Polym. Sci., 2003;88:3168-3175.

[44] Martín L, Ossó JO, Ricart S, Roig A, Garcíad O, Sastre R. J. Mater. Chem., 2008;18:207-213.

[45] Feher FJ, Newman DA, Walzer JF. J. Am. Chem. Soc., 1989;111:1741-1748.

[46] Feher FJ, Budzichowski TA, Blanski RL, Weller KJ, Ziller JW, Organometallics, 1991;10:2526-2528.

[47] Bassindale AR, Gentle TE. J. Mater. Chem., 1993;3:1319-1325.

[48] Feher FJ, Budzichowski TA, Polyhedron, 1995;14:3239-3253.

[49] Unno M, Alias SB, Arai M, Takada K, Tanaka R, Matsumoto H. Appl. Organomet. Chem., 1999; $13: 303-310$.

[50] Matějka L, Dukh O, Brus J, Simonsick Jr. WJ, Meissner B, J. Non-Cryst. Solids, 2000;270:34-47.

[51] Natta G, Corradini P, Nuovo. Cimento. Suppl. 1960;15:40-51. 
[52] Brückner S, Meille SV, Nature, 1989;340:455-457.

[53] Meille SV, Brückner S, Porzio W, Macromolecules, 1990;23:4114-4121.

[54] Auriemma F, De Rosa C, Boscato T, Corradini P. Macromolecules, 2001;34:4815-4826.

[55] Auriemma F, De Rosa C. Macromolecules, 2002;35:9057-9068.

[56] Campbell RA, Phillips PJ, Lin JS. Polymer, 1993;34:4809-4816.

[57] Brückner S, Meille SV, Petraccone V, Pirozzi B. Prog. Polym. Sci., 1991;16:361-404.

[58] HyperChem 7.1 for Windows; Hypercube, Inc., 2005.

[59] Nielsen LM, Mechanical properties of polymers, Rheinhold, NY, USA. (1962)

[60] Parikh AN, Schivley MA, Koo E, Seshadri K, Aurentz D, Mueller K, Allara DL. J. Am. Chem. Soc., 1997; 119:3135-3143.

[61] Shimojima A, Sugahara Y, Kuroda K, Bull. Chem. Soc. Jpn., 1997;70:2847-2853.

[62] Shimojima A, Sugahara Y, Kuroda K. J. Am. Chem. Soc., 1998;120:4528-4529.

[63] Wang R, Baran G, Wunder SL. Langmuir, 2000;16:6298-6305.

[64] Shimojima A, Kuroda K. Langmuir, 2002;18:1144-1149.

[65] Shimojima A, Liu Z, Ohsuna T, Terasaki O, Kuroda K. J. Am. Chem. Soc., 2005;127:14108-14116. 


\section{Figure Captions}

Figure 1 The spectral change due to the water-crosslinking reaction of EPR-g-VTMS/HTMS composites in the presence of (a) $\mathrm{PhSO}_{3} \mathrm{H}$ (benzenesulfonic acid, 5.0 $\times 10^{-4} \mathrm{~mol} / 100 \mathrm{~g}$ EPR resin) and (b) $\mathrm{PhNH}_{2}$ (aniline, $5.0 \times 10^{-4} \mathrm{~mol} / 100 \mathrm{~g}$ EPR resin) measured by ATR-FTIR technique. For peak assignment, see text.

Figure 2 Solid-state ${ }^{29} \mathrm{Si}$ CP/MAS NMR spectra of water-crosslinked EPR-g-VTMS/HTMS composites in the presence of (a) $\mathrm{PhSO}_{3} \mathrm{H}$ and (b) $\mathrm{PhNH}_{2}$ catalysts. Deconvolution of spectra was performed by using a Gaussian function. For symbol notation $\left(T^{m}\right)$, see text.

Figure 3 WAXS profiles of (A) virgin EPR resin, (B) uncrosslinked (as-prepared) and (C) watercrosslinked EPR-g-VTMS/HTMS composites in the presence of $\mathrm{PhSO}_{3} \mathrm{H}$ catalyst, and (D) uncrosslinked (asprepared) and (E) water-crosslinked EPR-g-VTMS/HTMS composites in the presence of $\mathrm{PhNH}_{2}$ catalyst. The (130) $\alpha$ and (117) $\gamma$ reflections at $2 \theta=18.6$ and $20.1^{\circ}$, respectively, of the $\alpha$ and $\gamma$ forms of isotactic polypropylene are indicated.

Figure 4 Effect of catalyst upon the stress-strain curves of water-crosslinked EPR- $g$-VTMS/HTMS composites [O: $\mathrm{PhNH}_{2}$-catalyzed EPR-g-VTMS/HTMS composite, $\triangle$ : $\mathrm{PhSO}_{3} \mathrm{H}$-catalyzed EPR-gVTMS/HTMS composite, $\square$ : uncrosslinked (as-prepared) EPR-g-VTMS/HTMS composite].

Figure 5 Typical FE-SEM micrographs of water-crosslinked EPR-g-VTMS/HTMS composites in the presence of (a) $\mathrm{PhSO}_{3} \mathrm{H}$ and (b), (c), (d) $\mathrm{PhNH}_{2}$ catalysts. (a)(b) low-magnification; (c) high-magnification; and (d) cross section using liquid nitrogen. 


\section{$\underline{\text { Scheme titles }}$}

Scheme 1 Preparation procedure of water-crosslinked EPR-g-VTMS/HTMS composites.

Scheme 2 Schematic representation of cis-syndiotactic ladder conformation of poly $(n$-hexyl silsesquioxane)s. The spacing value was obtained from the conformation calculated by the AM1 method.

Scheme 2 Schematic representation of the proposed model of the resulting layered structure in watercrosslinked EPR-g-VTMS/HTMS composites. 
Figure 1
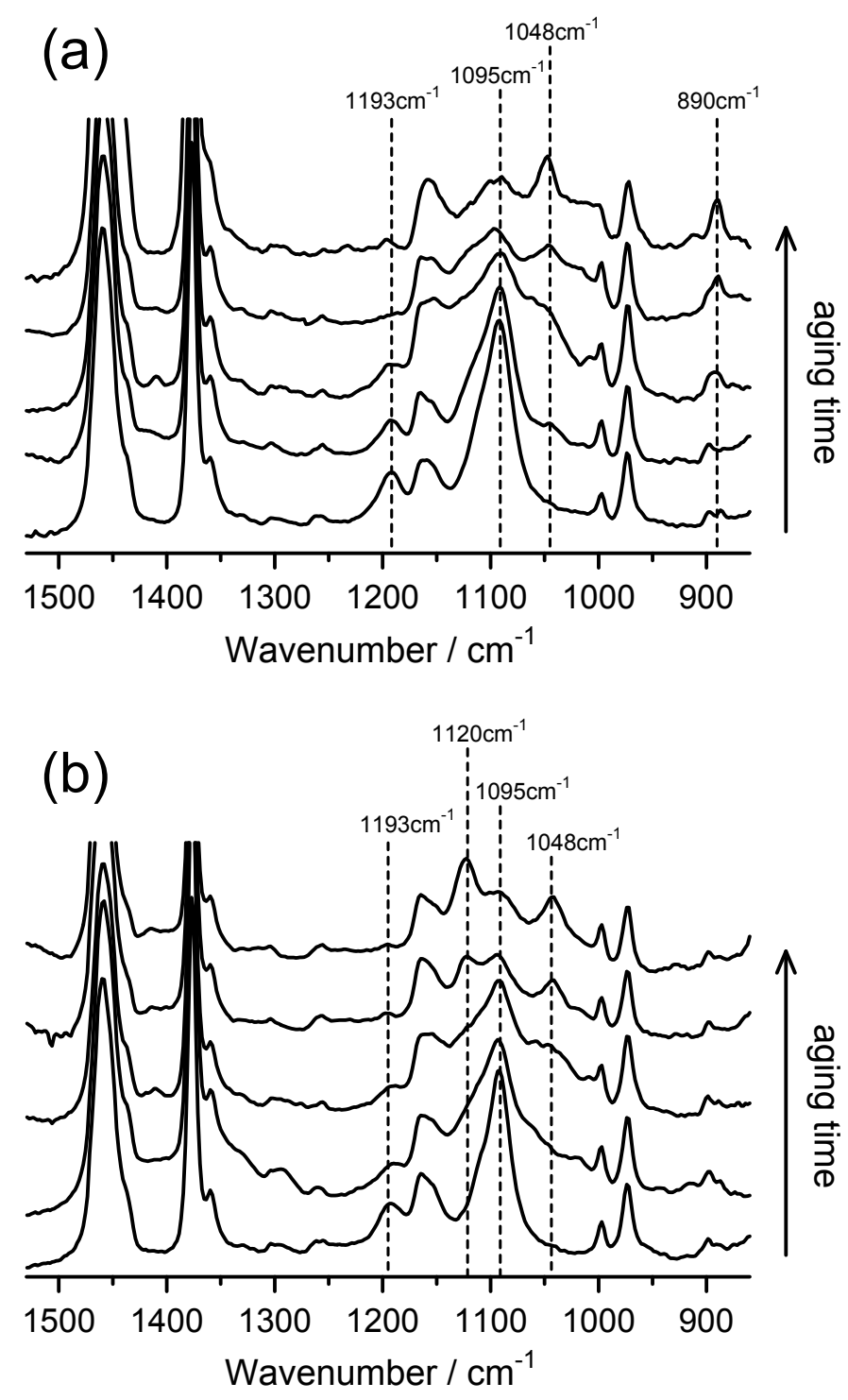
Figure 2

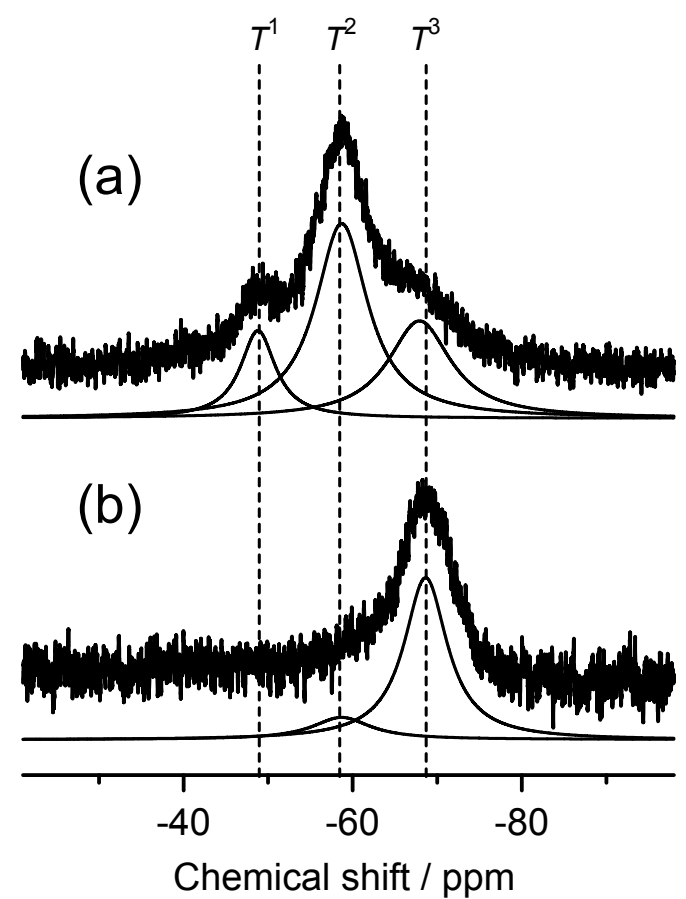


Figure 3

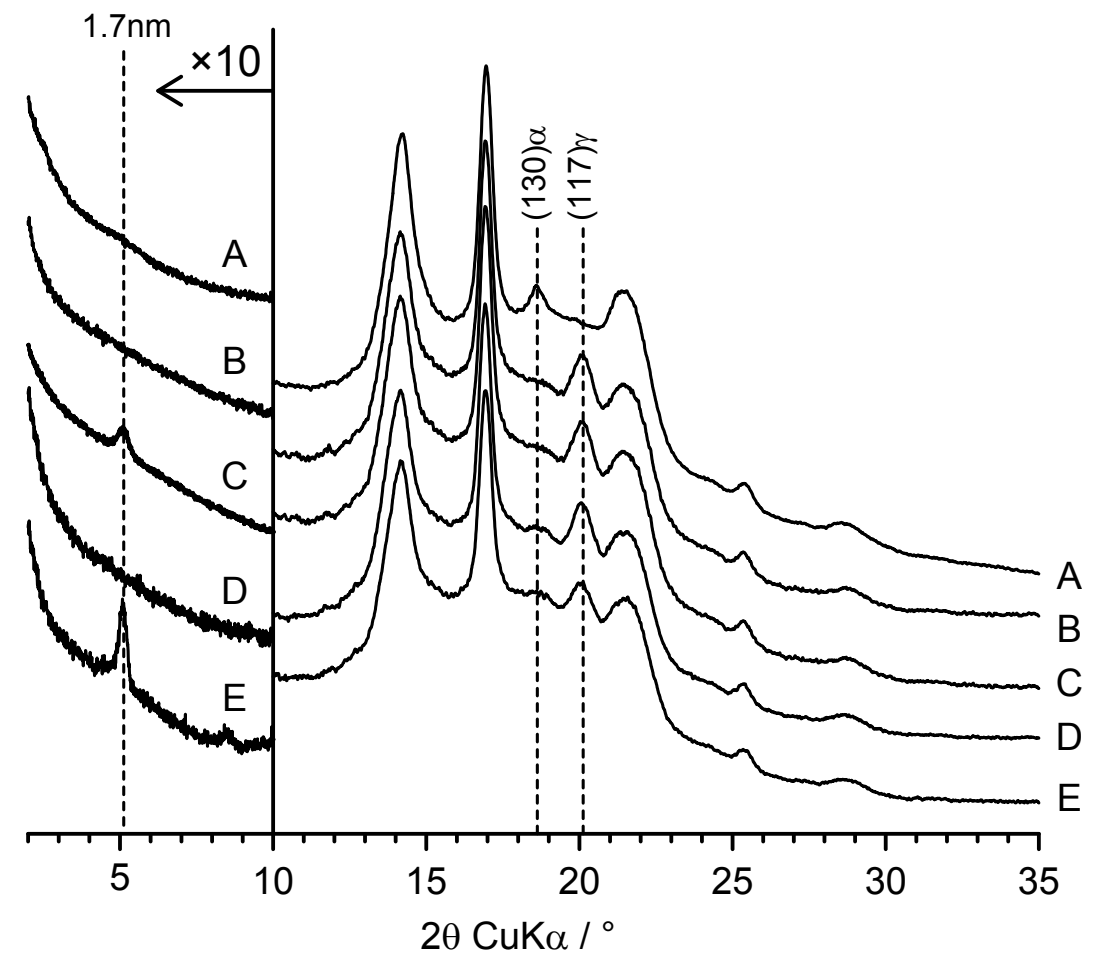


Figure 4

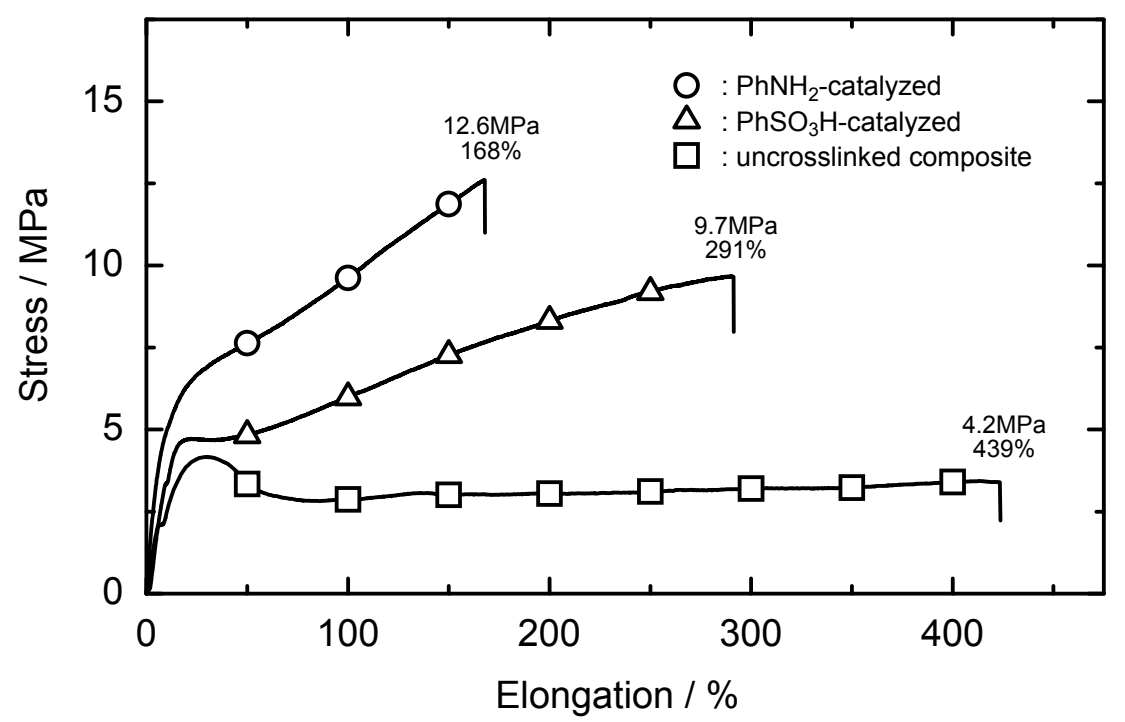




\section{Figure 5}
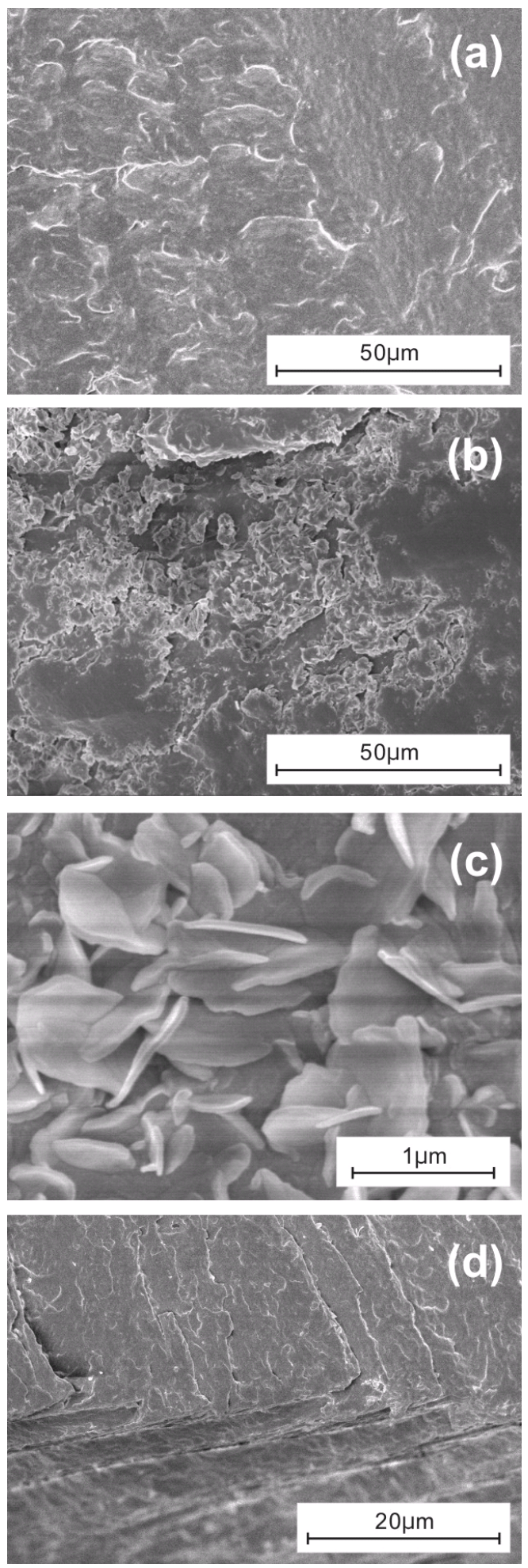
Scheme 1

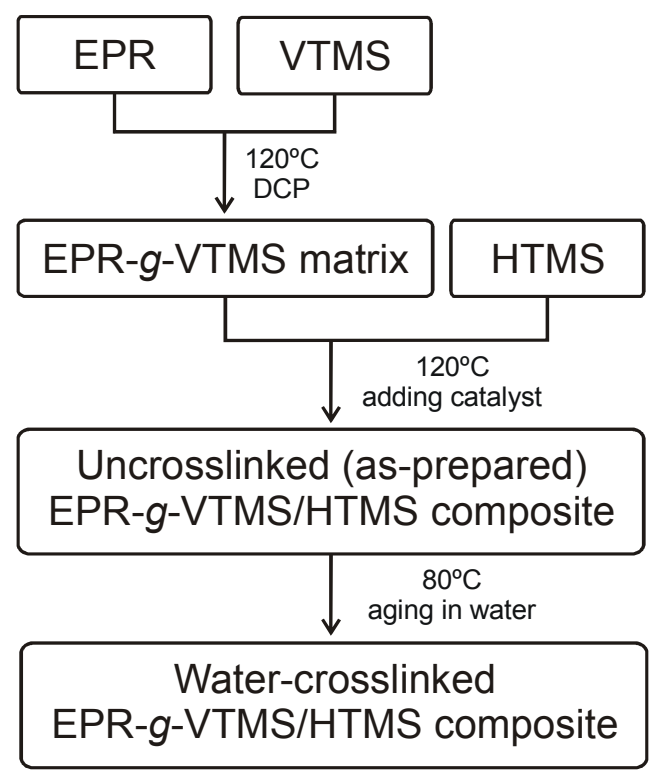


Scheme 2

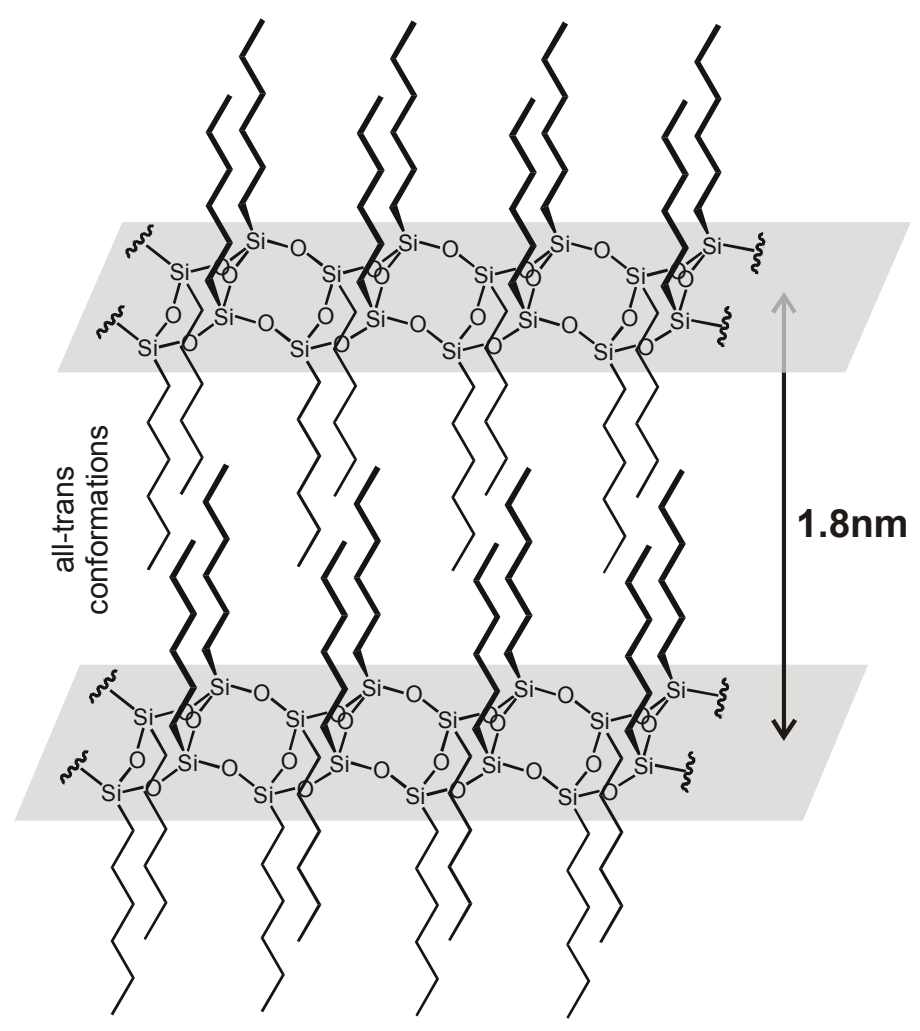




\section{Scheme 3}

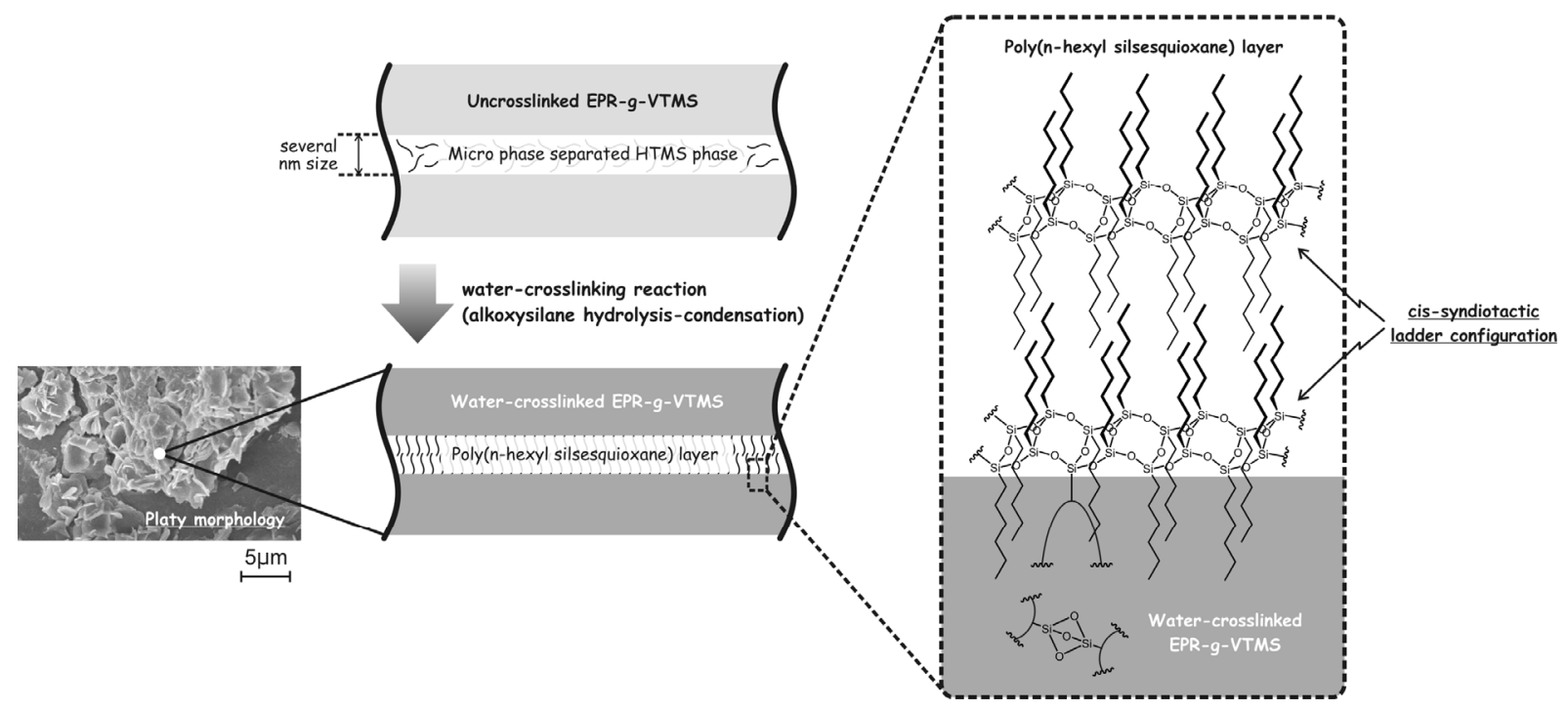

